Article

\title{
Methanolic Extract of Ganoderma lucidum Induces Autophagy of AGS Human Gastric Tumor Cells
}

\author{
Filipa S. Reis ${ }^{1,2,3,4}$, Raquel T. Lima ${ }^{1,2,5}$, Patricia Morales ${ }^{3}$, Isabel C. F. R. Ferreira ${ }^{4, *}$ \\ and M. Helena Vasconcelos $1,2,6, *$
}

1 I3S - Instituto de Investigação e Inovação em Saúde, Universidade do Porto, Porto 4099-002, Portugal; E-Mails: freis@ipatimup.pt (F.S.R.); rlima@ipatimup.pt (R.T.L.)

2 Cancer Drug Resistance Group, Institute of Molecular Pathology and Immunology of the University of Porto (IPATIMUP), Rua Júlio Amaral de Carvalho, 45, Porto 4200-135, Portugal

3 Departamento de Nutrición y Bromatología II, Facultad de Farmacia, Universidad Complutense de Madrid (UCM), Pza Ramón y Cajal, s/n, E-28040 Madrid, Spain; E-Mail: patricia.morales@farm.ucm.es

4 Mountain Research Center (CIMO), ESA, Polytechnic Institute of Bragança, Apartado 1172, Bragança 5301-855, Portugal

5 Department of Pathology and Oncology, Faculty of Medicine, University of Porto, Alameda Professor Hernâni Monteiro, Porto 4200-319, Portugal

6 Laboratory of Microbiology, Department of Biological Sciences, Faculty of Pharmacy, University of Porto, Rua de Jorge Viterbo Ferreira n. ${ }^{\circ} 228$, Porto 4050-313, Portugal

* Authors to whom correspondence should be addressed; E-Mails: iferreira@ipb.pt (I.C.F.R.F.); hvasconcelos@ipatimup.pt (M.H.V.); Tel.: +351-273-303-219 (I.C.F.R.F.); +351-225-570-700 (M.H.V.); Fax: +351-273-325-405 (I.C.F.R.F.); +351-225-570-799 (M.H.V.).

Academic Editor: Nancy D. Turner

Received: 28 July 2015 / Accepted: 23 September 2015 / Published: 29 September 2015

Abstract: Ganoderma lucidum is one of the most widely studied mushroom species, particularly in what concerns its medicinal properties. Previous studies (including those from some of us) have shown some evidence that the methanolic extract of G. lucidum affects cellular autophagy. However, it was not known if it induces autophagy or decreases the autophagic flux. The treatment of a gastric adenocarcinoma cell line (AGS) with the mushroom extract increased the formation of autophagosomes (vacuoles typical from autophagy). Moreover, the cellular levels of LC3-II were also increased, and the cellular levels of p62 decreased, confirming that the extract affects cellular autophagy. Treating the cells with the extract 
together with lysossomal protease inhibitors, the cellular levels of LC3-II and p62 increased. The results obtained proved that, in AGS cells, the methanolic extract of G. lucidum causes an induction of autophagy, rather than a reduction in the autophagic flux. To our knowledge, this is the first study proving that statement.

Keywords: Ganoderma lucidum; methanolic extract; antitumor potential; programmed cell death (PCD); autophagy

\section{Introduction}

One of the hallmarks of cancer is the ability of tumor cells to resist cell death [1]. Therefore, therapies based on the induction of programmed cell death (PCD) constitute an area of scientific interest.

Being a "self-digestive" process, autophagy is considered a mechanism of cell survival, which allows the cell to obtain nutrients under deprivation conditions [2]. However, recent investigations have shown that, despite its importance as a homeostatic evolutionary process in all cells, autophagy may also be considered a mechanism of cell death. Actually, cells exposed to prolonged stress and continuous autophagy can eventually "commit suicide" [3].

Mushrooms are a proven source of extracts and/or compounds with antitumor properties, namely with capacity to induce PCD [4-6]. Thus, the identification and chemical characterization of mushroom extracts that induce PCD in human tumor cells may allow the discovery of novel compounds that can be used as drugs or nutraceuticals.

Ganoderma lucidum (Curtis) P. Karst. has been used as a functional food and as preventive medicine in the Far East and has become a popular dietary supplement in Western countries. This mushroom has been extensively reported as having important bioactive properties, including antitumor activity via induction of programmed cell death (PCD) [7-9]. Moreover, some of the G. lucidum extracts and/or isolated compounds have been previously described as modulators of autophagy in several human tumor cell lines [10-13]. Indeed, some of us have previously report that a methanolic extract of G. lucidum fruiting body (obtained by extraction at room temperature) inhibited the growth of a human gastric tumor cell line, through a mechanism which involved cellular autophagy [13]. However, it is not known if the extract is an inducer of autophagy or an inhibitor of the autophagic flux.

In the present work we aimed at studying a presumably more potent methanolic extract from G. lucidum, obtained by cold extraction, in order to understand if the previously observed autophagy modulation was due to an increase in autophagy or to a decrease in the late stages of autophagy (i.e., a block in the autophagic flux). Moreover, the phenolic content of the extract was determined and cellular treatments with the phenolics found in the extract were performed, in order to verify if they were responsible for the extract bioactivity. 


\section{Results and Discussion}

\subsection{Chemical Characterization of the Methanolic Extract}

The methanolic extract obtained by cold extraction was chemically characterized, revealing the presence of $p$-hydroxybenzoic acid (123 $\pm 9 \mu \mathrm{g} / \mathrm{g}$ extract), $p$-coumaric acid (80 $\pm 6 \mu \mathrm{g} / \mathrm{g}$ extract) and cinnamic acid $(59 \pm 6 \mu \mathrm{g} / \mathrm{g}$ extract). Compared with the profile of the methanolic extract obtained at room temperature: $p$-hydroxybenzoic acid ( $82 \pm 4 \mu \mathrm{g} / \mathrm{g}$ extract), $p$-coumaric acid (53 $\pm 3 \mu \mathrm{g} / \mathrm{g}$ extract) and cinnamic acid ( $40 \pm 3 \mu \mathrm{g} / \mathrm{g}$ extract) [13], the former revealed a higher concentration of all phenolic and related compounds (Figure 1).

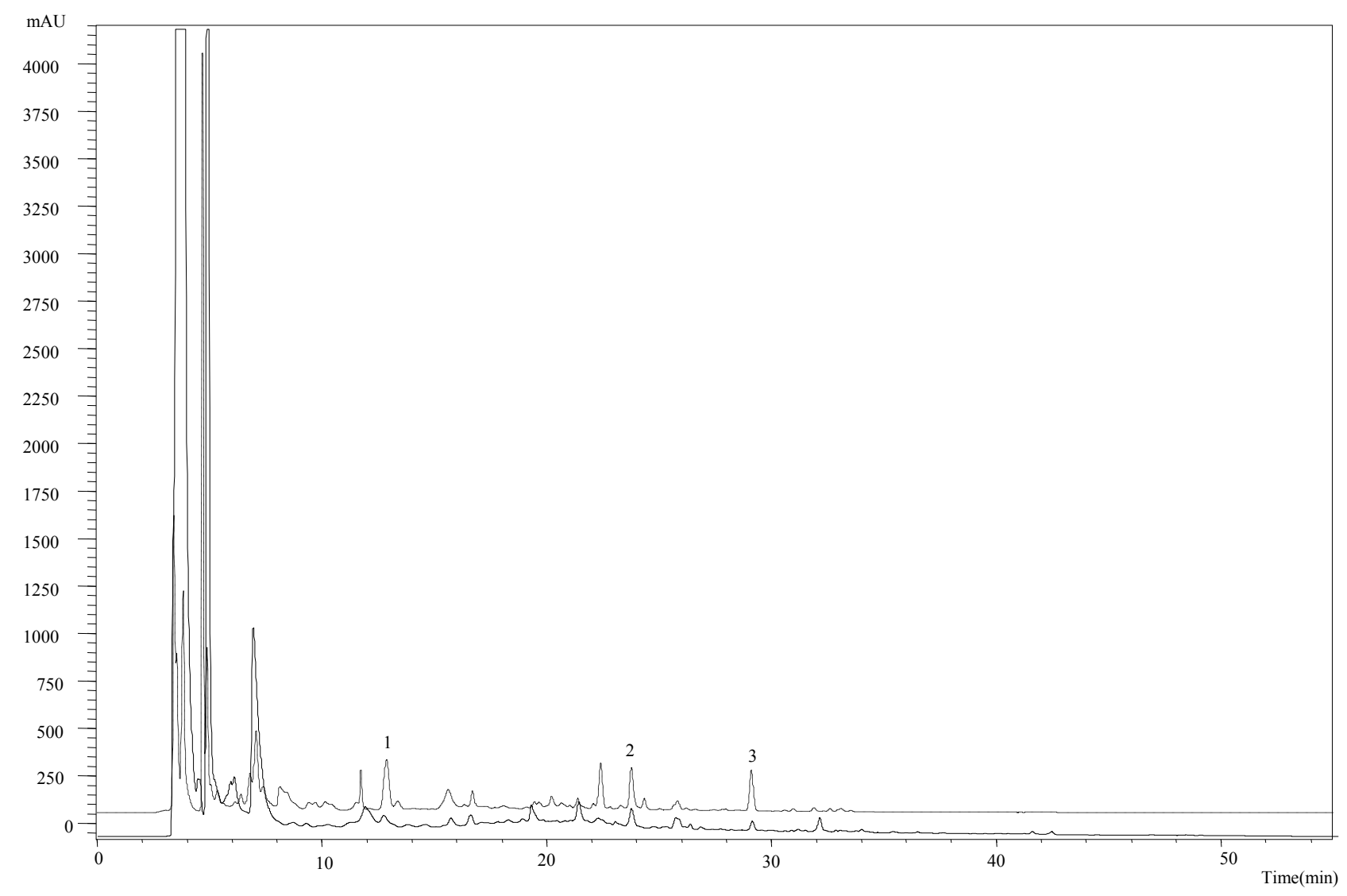

Figure 1. Phenolic acids profile of Ganoderma lucidum cold extract (-----) and room temperature extract $(-) .1-p$-Hydroxybenzoic acid; $2-p$-coumaric acid; 3 - cinnamic acid.

\subsection{Antitumor Potential of the New Obtained Extract}

In order to confirm if the cold extract presented antitumor activity, the new extract was tested against a panel of four human tumor cell lines (Table 1).

Even though the studies were not carried out at the same time, the cold methanolic extract here studied presented a more potent in vitro cell growth inhibitory activity than the previously studied extract (prepared at room temperature), under the same laboratorial conditions and using the same cell lines [13]. This could be attributed to the higher content of phenolic acids and related compounds observed in the cold extract. Therefore, the following study was performed with this extract of the G. lucidum fruiting body and in the AGS cell line. 
Table 1. GI50 concentrations of the cold methanolic extract of G. lucidum fruiting body in various human tumor cell lines ${ }^{\text {a }}$.

\begin{tabular}{ccccc}
\hline \multicolumn{5}{c}{ Ganoderma lucidum Methanolic Extract } \\
\hline \multirow{2}{*}{$\mathrm{GI}_{50}(\mu \mathrm{g} / \mathrm{mL})$} & NCI-H460 & HCT-15 & MCF-7 & AGS \\
& $77.9 \pm 3.3$ & $70.0 \pm 2.4$ & $67.2 \pm 3.1$ & $66.6 \pm 4.4$ \\
\hline
\end{tabular}

${ }^{a}$ Values correspond to the mean \pm SE of at least three independent experiments. The maximum DMSO
concentration used was $0.3 \%$ and did not interfere with cell growth $(\%$ cell growth relatively to Blank cells
treated with medium was as follows: $115.7 \% \pm 0.12 \%$ in AGS cells, $108.6 \% \pm 0.07 \%$ in NCI-H460 cells,
$99.2 \% \pm 0.04 \%$ in HCT- 15 cells and $106.9 \% \pm 0.05 \%$ in MCF- 7 cells). Previously published GI 50 results
with an extract obtained at room temperature were as follows: $107.5 \pm 5.3 \mu \mathrm{g} / \mathrm{mL}$ in NCI-H460 cells,
$103.4 \pm 13.2 \mu \mathrm{g} / \mathrm{mL}$ in HCT-15 cells, $112.6 \pm 6.7 \mu \mathrm{g} / \mathrm{mL}$ in MCF- 7 cells and $93.3 \pm 9.1 \mu \mathrm{g} / \mathrm{mL}$ in AGS cells [13].

\subsection{Effect of G. lucidum Methanolic Extract in AGS Cellular Autophagy}

AGS cells were transfected with a mCherry-LC3 expression vector and were then treated for $48 \mathrm{~h}$ with two concentrations of the extract ( $\mathrm{GI}_{50}$ and $2 \times \mathrm{GI}_{50}$ concentrations). These concentrations were selected since they inhibited the growth of the cell population but did not cause much cell death (Supplementary Material). The obtained results indicate that this treatment induced the presence of LC3 within autophagic vacuoles (Figure 2).
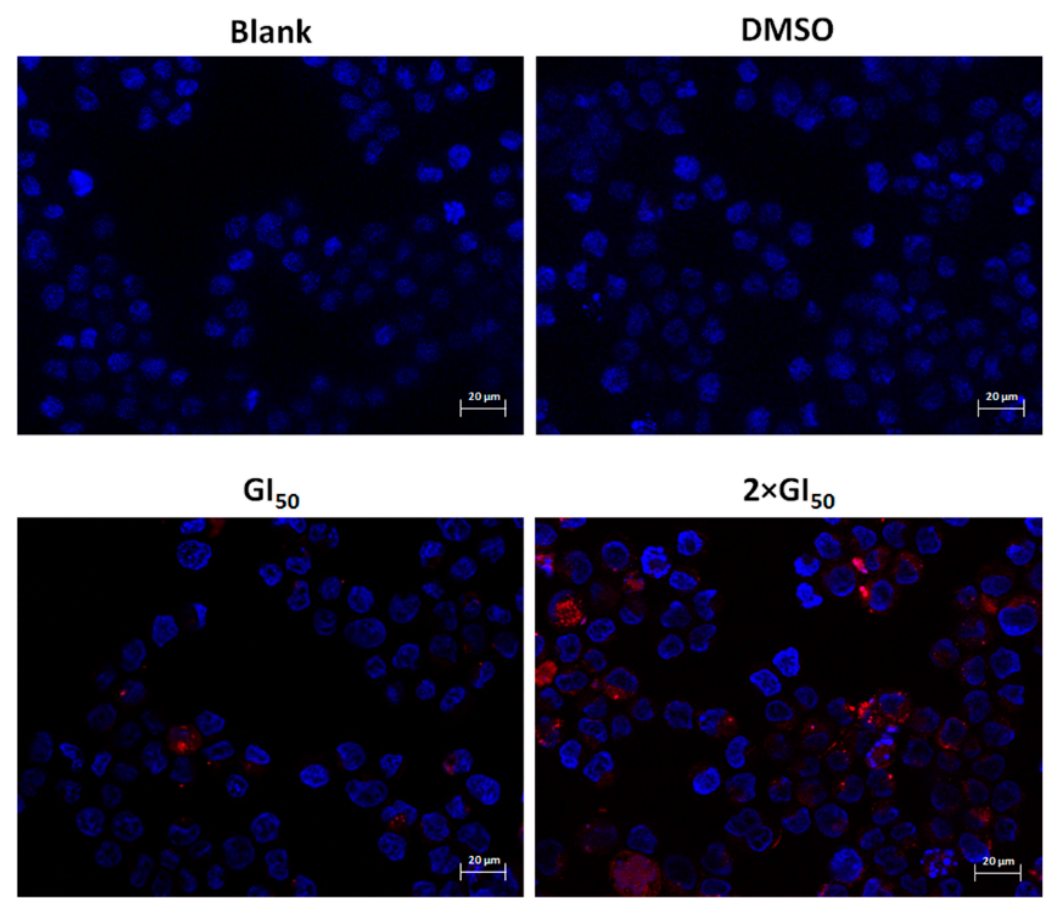

Figure 2. Analysis of the presence of autophagic vacuoles following treatment with G. lucidum methanolic extract, by fluorescence microscopy. Cells were transfected for $24 \mathrm{~h}$ with LC3 mCherry vector (red) and further treated for $48 \mathrm{~h}$ with: medium only (Blank), with the methanolic extract (at GI50 and $2 \times$ GI50 concentrations) or with the extract solvent (DMSO) corresponding to the higher concentration of the extract. Nuclei were stained with DAPI (blue). Images are representative of two experiments. Bar corresponds to $20 \mu \mathrm{m}$. 
This effect was preferentially observed in cells treated with a concentration of $133.2 \mu \mathrm{g} / \mathrm{mL}$ of the extract. The presence of autophagic vacuoles (autophagosomes), typical of autophagy, was thus confirmed in AGS cells following treatment with the extract.

It is known that Beclin-1 binds to the vacuolar sorting protein 34 (Vps34, a class III phosphatidylinositol-3 kinase), and that this complex is involved in the initial step of autophagosomes formation [14]. Therefore, the expression levels of such proteins in AGS cells following $48 \mathrm{~h}$ treatment with the two tested concentrations of the extract were investigated. Nevertheless, no differences in the expression levels of these proteins were found at this time point (Figure 3).

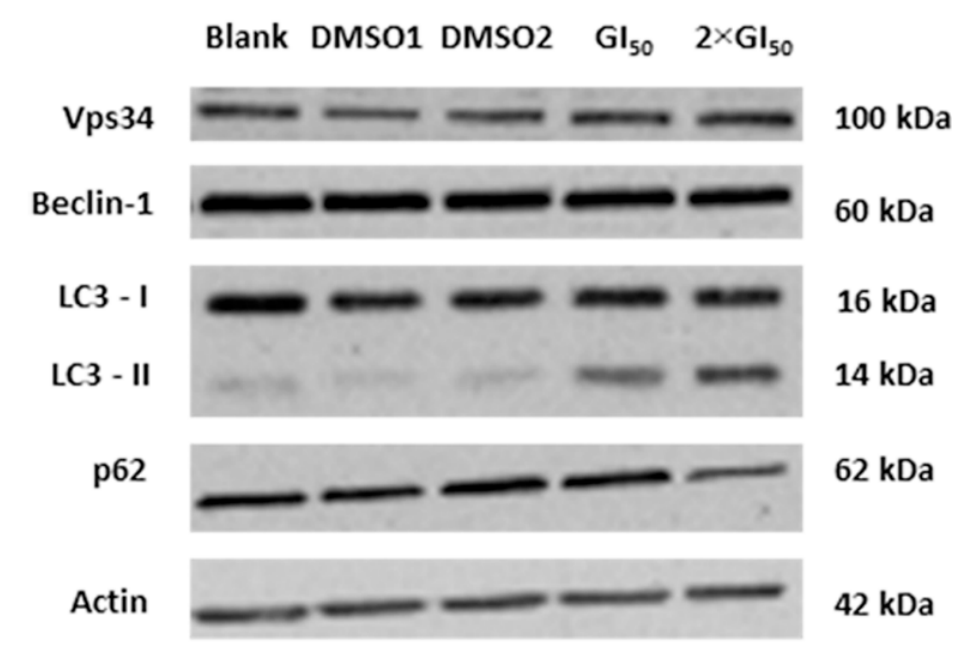

Figure 3. Analysis of the levels of the autophagy-related proteins Vps34, Beclin-1, LC3-I, LC3-II and p62, following treatment with G. lucidum methanolic extract, analyzed by Western blot. Cells were treated for $48 \mathrm{~h}$ with: medium only (Blank), with the methanolic extract (at GI50 and $2 \times \mathrm{GI}_{50}$ concentrations) or the corresponding volumes of the extract solvent (DMSO). Actin was used as loading control. Image is representative of three independent experiments.

In addition, the levels of other autophagy-related proteins (LC3 and p62) were analyzed following the same treatment. LC3 turnover is usually monitored to follow the autophagic flux. This is based on the measurement of the levels of LC3-II, which are known to increase upon autophagy induction and decrease thereafter (since it is degraded in the autolysosomes) [15,16]. Thus, an increase in LC3-II protein levels is expected to be found at the beginning of the autophagy mechanism, as this protein is associated with autophagosomes formation. On the other hand, in the course of the autophagic flow a decline in these levels is expected, since the autophagic vacuoles are ultimately degraded. Furthermore, p62 (another autophagy substrate) can also be used to monitor the autophagic flux. This protein directly interacts with LC3 and, as the LC3-II present in the inner membrane of the autophagosomes is degraded by lysosomal proteases, the p62 previously trapped by LC3 is selectively incorporated into autophagosomes and is degraded by autophagy. Accordingly, the total cellular levels of p62 correlate inversely with autophagic activity and a decrease in p62 levels is expected with the induction of autophagy [15,17]. Results showed that this treatment caused an increase in the cellular levels of LC3-II, together with a slight reduction in the levels of p62, particularly with the highest concentration studied (Figure 3). These results are in agreement with an apparent induction of autophagy. However, the observed results could be due to an 
induction of autophagy or to a decrease of the autophagic flux. To confirm this, the levels of LC3-II and p62 were further analyzed following cellular treatment with the extract together with (or without) the lysossomal protease inhibitors of the formation of the autophagolysosome (E-64d/pepstatin, known later-stage autophagy inhibitors) [18].

Results showed that the levels of both LC3-II and p62 proteins increased following treatment of cells with the extract together with the inhibitors, when compared to the treatment with the extract alone (Figure 4). These results confirm that this extract of G. lucidum is an inducer of autophagy.

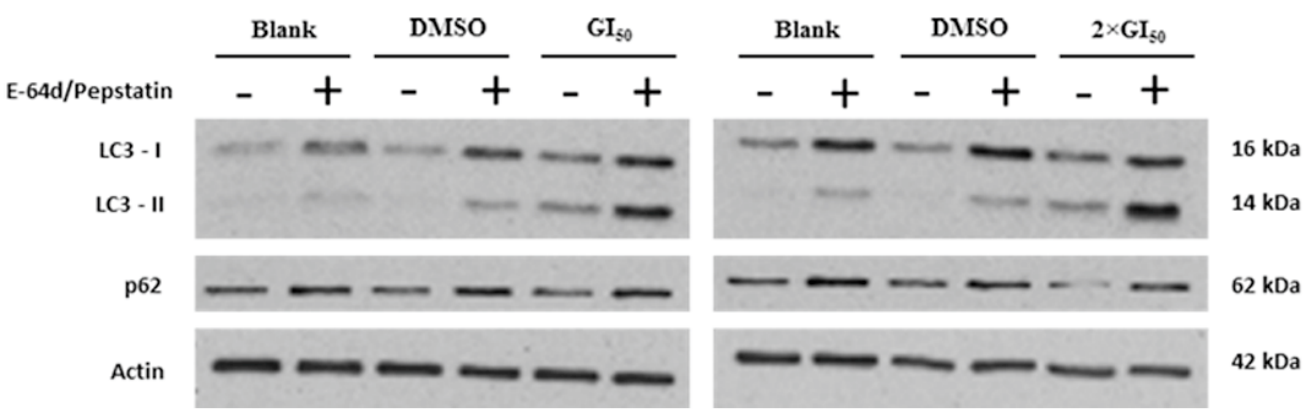

Figure 4. Effect of co-treatment with G. lucidum methanolic extract together with E-64d/pepstatin in LC3-II and p62 levels, analyzed by Western blot. Cells were treated for $48 \mathrm{~h}$ with medium (Blank), with the solvent (DMSO) or with the extract (GI50 and $2 \times \mathrm{GI}_{50}$ concentrations), together with (or without) E-64d/pepstatin $(15 \mu \mathrm{g} / \mathrm{mL})$. Actin was used as loading control. Results are representative of 3 independent experiments.

The presented results further support the fact that the methanolic extract of G. lucidum may be used as a source of compounds which induce autophagy.

Since some phenolic acids were identified in the methanolic extract of G. lucidum, namely $p$-coumaric and $p$-hydroxybenzoic acids and the related compound cinnamic acid, we also tried to assess whether these compounds were responsible for the studied bioactivity. The levels of the autophagy marker LC3-II were analyzed in AGS cells following treatment with relatively high concentrations of these compounds (250 $\mu \mathrm{M}$ and $500 \mu \mathrm{M}$ ), but no significant alterations were observed (Figure 5), indicating that these compounds are probably not involved, at least not on their own, in the induction of autophagy that was observed in cells treated with the extract.

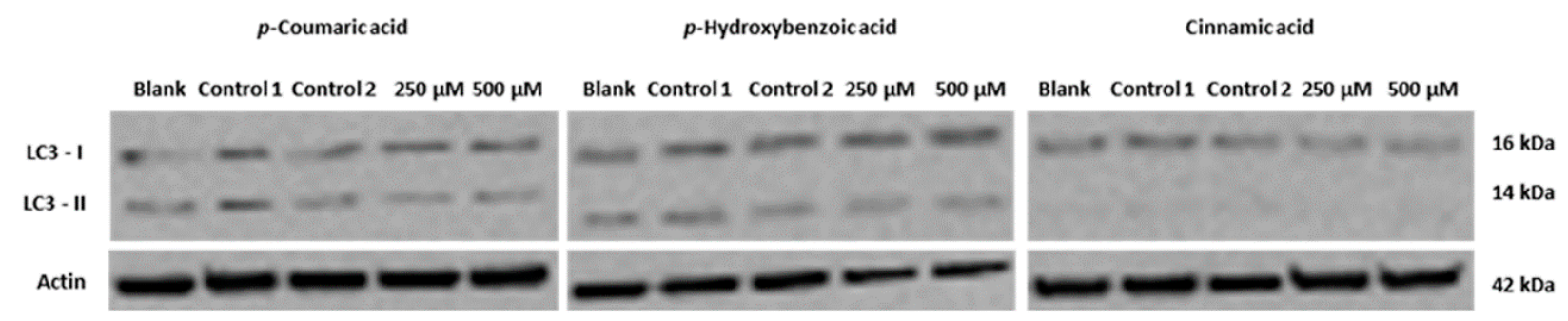

Figure 5. Analysis of the levels of the autophagy marker LC3II in AGS cells following $48 \mathrm{~h}$ treatment with $p$-coumaric acid, $p$-hydroxybenzoic acid or cinnamic acid, analyzed by Western blot. Cells were treated for $48 \mathrm{~h}$ with medium (Blank), with the solvent (DMSO:water; 1:1 $v / v$; controls 1 and 2) or with the compounds (at 250 and $500 \mu \mathrm{M}$ ). Actin was used as loading control. Blot is representative of two independent experiments. 
Additionally, we tried to verify if some derivatives of G. lucidum phenolic acids (synthesized from the main phenolic acids present in the extract— $-p$-hydroxybenzoic and cinnamic acids; Heleno et al. [19]) were inducers of autophagy. However, none of the synthesized compounds tested (methylated and acetyl glucuronated methyl esters derivatives) were capable of increasing the cellular LC3-II levels, up to the concentrations tested $(20,40$, and $60 \mu \mathrm{M}$, data not shown). Nevertheless, it's possible that the phenolic compounds may act synergistically with other compounds. This concomitant effect has been proven both in vitro and in vivo [20-24], and may be a possible justification for the results obtained.

\section{Experimental Section}

\subsection{Collection and Sample Preparation}

Wild samples of Ganoderma lucidum (Curtis) P. Karst. were harvested in Bragança (Northeastern Portugal) in July 2011. The taxonomic identification and sample preparation was made as described by Heleno et al. [25].

\subsection{Preparation and Chemical Characterization of Ganoderma lucidum Methanolic Extract}

A cold methanolic extraction was applied to G. lucidum fruiting bodies, by mixing the dry powder $(\sim 1 \mathrm{~g})$ with methanol $(30 \mathrm{~mL})$ at $-20{ }^{\circ} \mathrm{C}$ (freezer) for $2 \mathrm{~h}$. After sonication for $15 \mathrm{~min}$, the extract was filtered and the residue was then extracted with two additional $30 \mathrm{~mL}$ portions of methanol; combined extracts were concentrated in a rotavapor. The obtained extract was chromatographically characterized according to other authors [25].

To the accomplishment of biological assays, the residue extracts were re-dissolved in DMSO $(100 \mathrm{mg} / \mathrm{mL})$.

\subsection{Screening of the Growth Inhibitory Activity in Human Tumor Cell Lines}

The effects of the G. lucidum methanolic extract on the growth of human tumor cell lines were evaluated with the sulforhodamine B (SRB) assay [26]. Four human tumor cell lines were used: AGS (gastric adenocarcinoma), MCF-7 (breast adenocarcinoma), NCI-H460 (non-small cell lung cancer) and HCT-15 (colorectal adenocarcinoma), and the screening was performed as already described by Oliveira et al. [13].

\subsection{Transfection with LC3-mCherry Expression Vector}

Cells were plated in 24 -well plates $\left(3.75 \times 10^{4}\right.$ cells/well $)$ and allowed to adhere for $24 \mathrm{~h}$. Transfection with the vector LC3-mCherry (a kind gift from Prof. T. Johansen) [27] was then carried out using Lipofectamine (Invitrogen) according to manufacturer's instructions. As described by Birame et al. [28] during the initial $4 \mathrm{~h}$ of transfection, cells were incubated with medium containing 5\% FBS, which was then replaced by medium containing $10 \%$ FBS. Following $24 \mathrm{~h}$ of transfection, medium was removed and cells were treated for $48 \mathrm{~h}$ with medium (Blank); with the studied methanolic extract from G. lucidum (at GI50 concentration of $66.6 \mu \mathrm{g} / \mathrm{mL}$, and $2 \times \mathrm{GI}_{50}$ concentration of $133.2 \mu \mathrm{g} / \mathrm{mL}$, as previously determined with the SRB assay, Table 1); or with the extract solvent (DMSO) corresponding to the higher concentration. 
Cells were then fixed in 4\% paraformaldehyde in PBS and analyzed in a fluorescence microscope (Axio Imager.Z1 coupled with ApoTome Imaging System microscope, Zeiss, Oberkochen, Germany).

\subsection{Expression of Autophagy-Related Proteins}

AGS cells were plated at $1.5 \times 10^{5}$ cells/well in 6-well plates and incubated for $24 \mathrm{~h}$. Cells were then treated with the methanolic extract of G. lucidum at its $\mathrm{GI}_{50}$ and $2 \times \mathrm{GI}_{50}$ concentrations. Blank cells (treated with medium) or control cells (treated with DMSO, corresponding to the $\mathrm{GI}_{50}$ and $2 \times \mathrm{GI}_{50}$ concentrations of the extract) were also included. For treatments with the phenolic acids and related compounds, cells were treated with $p$-coumaric, $p$-hydroxybenzoic and cinnamic acids for $48 \mathrm{~h}$ with concentrations of 250 and $500 \mu \mathrm{M}$ (parental compounds) and 20, 40, and $60 \mu \mathrm{M}$ (methylated and acetyl glucuronated methyl esters derivatives). Blank and control cells were also included.

Following $48 \mathrm{~h}$ of treatment, AGS cells were lysed and protein lysates were quantified according to manufacturer's instructions and $20 \mu \mathrm{g}$ of protein loaded on 12\% SDS-PAGE gel [29]. After electrophoretic transfer into nitrocellulose membranes (GE Healthcare, Oeiras, Portugal), membranes were incubated with the following primary antibodies: rabbit anti-VPS34 (1:1000, Cell Signaling, Danvers, MA, USA), rabbit Beclin-1 (1:1000, Cell Signaling), rabbit anti-Light Chain 3 B, LC3 (1:1000, Cell Signaling), rabbit anti-p62 (1:5000, Enzo, New York, NY, USA), goat anti-Actin antibody (1:2000, Santa Cruz Biotechnology, Heidelberg, Germany) and with the corresponding secondary antibody: goat anti-rabbit IgG-HRP (1:2000, Santa Cruz Biotechnology), donkey anti-goat IgG-HRP (1:2000, Santa Cruz Biotechnology) or goat anti-mouse IgG-HRP (1:2000, Santa Cruz Biotechnology). Signal was detected using Amersham ${ }^{\text {TM }}$ ECL Western Blotting Detection Reagents (GE Healthcare), the Amersham Hyperfilm ECL (GE Healthcare) and the Kodak GBX developer and fixer (Sigma-Aldrich, Sintra, Portugal).

\subsection{Treatment with Autophagy Inhibitors E-64d/Pepstatin}

AGS cells were plated in 6-well plates $\left(1.5 \times 10^{5}\right.$ cells/well $)$ and allowed to adhere for $24 \mathrm{~h}$. Cells were then treated for $1 \mathrm{~h}$ with $15 \mu \mathrm{g} / \mathrm{mL}$ of the lysossomal inhibitors E-64d (AppliChem, Darmstadt, Germany) and Pepstatin A (Cayman Chemical, Ann Arbor, MI, USA) and then co-incubated for $48 \mathrm{~h}$ with the GI50 and $2 \times \mathrm{GI}_{50}$ concentrations of the studied methanolic extract. Blank and control cells were also included. Protein expression analysis was carried out by Western blot, as described above.

\subsection{Statistical Analysis}

All experimental data are presented as mean values \pm standard deviation (SD) or standard error (SE) from at least three independent experiments (most of them performed in duplicate).

\section{Conclusions}

In conclusion, G. lucidum methanolic extract increased the formation of autophagosomes, increased the cellular levels of LC3-II and decreased the cellular levels of p62, confirming that the extract affects cellular autophagy in AGS cells. Additionally, treatment with the extract together with lysossomal protease inhibitors caused a further increase in the cellular LC3-II levels together with an increase in p62 levels proving that, in these cells, the methanolic extract of G. lucidum cause an induction of autophagy 
rather than a reduction in the autophagic flux. Further studies are still needed to identify the bioactive compound(s) present in the tested extract which may be responsible for the observed autophagy induction. Moreover, future work will allow elucidating which are the intracellular signaling cascades involved in autophagy induced by G. lucidum or by their bioactive compounds, namely the PI3K/mTOR or the AMPK signaling pathways.

\section{Supplementary Materials}

Supplementary materials can be accessed at: http://www.mdpi.com/1420-3049/20/10/17872/s1.

\section{Acknowledgments}

IPATIMUP integrates the i3S Research Unit, which is partially supported by FCT, the Portuguese Foundation for Science and Technology. This work is funded by FEDER funds through the Operational Programme for Competitiveness Factors-COMPETE and National Funds through the FCT-Foundation for Science and Technology, under the projects "PEst-C/SAU/LA0003/2013", NORTE-07-0162-FEDER00018-Contributos para o reforço da capacidade do IPATIMUP enquanto actor do sistema regional de inovação and NORTE-07-0162-FEDER-000067-Reforço e consolidação da capacidade infraestrutural do IPATIMUP para o sistema regional de inovação, both supported by Programa Operacional Regional do Norte (ON.2-O Novo Norte), through FEDER funds under the Quadro de Referência Estratégico Nacional (QREN). The authors thank COMPETE/QREN/EU for the financial support to CIMO (strategic project PEst-OE/AGR/UI0690/2014) and L. Barros. Authors also thank Foundation for Science and Technology (FCT, Portugal) for R.T. Lima grant (SFRH/BPD/68787/2010) and QREN for the grant of F.S. Reis (NORTE-07-0124-FEDER-000023).

\section{Author Contributions}

M.H. Vasconcelos, I.C.F.R. Ferreira and P. Morales conceived the study. F.S. Reis, M.H. Vasconcelos and I.C.F.R. Ferreira designed the experiments. F.S. Reis carried out the assays. F.S. Reis and R.T. Lima performed data organization and analysis of the results. F.S. Reis, I.C.F.R. Ferreira and M.H. Vasconcelos wrote the manuscript. P. Morales and R.T. Lima revised the manuscript.

\section{Conflicts of Interest}

The authors declare no conflict of interest.

\section{References}

1. Hanahan, D.; Weinberg, R.A. Hallmarks of cancer: The next generation. Cell 2011, 144, 646-674.

2. Tan, M.L.; Ooi, J.P.; Ismail, N.; Moad, A.I.H.; Muhammad, T.S.T. Programmed cell death pathways and current antitumor targets. Pharm. Res. 2009, 26, 1547-1560.

3. Yang, Z.J.; Chee, C.E.; Huang, S.; Sinicrop, F.A. The role of autophagy in cancer: Therapeutic implications. Mol. Cancer Ther. 2011, 10, 1533-1541.

4. Ferreira, I.C.F.R.; Vaz, J.A.; Vasconcelos, M.H.; Martins, A. Compounds from wild mushrooms with antitumor potential. Anticancer Agents Med. Chem. 2010, 10, 424-436. 
5. Patel, S.; Goyal, A. Recent developments in mushrooms as anti-cancer therapeutics: A review. 3 Biotech 2012, 2, 1-15.

6. Reis, F.S.; Morales, P.; Ferreira, I.C.F.R.; Vasconcelos, M.H. Mushrooms as a source of compounds that induce programmed cell death in tumor cells. In Recent Progress in Medicinal Plants; Govil, J.N., Ed.; Studium Press LLC: Houston, TX, USA, 2015; Volume 43-Phytotherapeutics II, in press.

7. Harhaji Trajković, L.M.; Mijatović, S.A.; Maksimović-Ivanić, D.D.; Stojanović, I.D.; Momčilović, M.B.; Tufegdžić, S.J.; Maksimović, V.M.; Marjanovi, Ž.S.; Stošić-Grujičić, S.D. Anticancer properties of Ganoderma lucidum methanol extracts in vitro and in vivo. Nutr. Cancer 2009, 61, 696-707.

8. Calviño, E.; Manjón, J.L.; Sancho, P.; Tejedor, M.C.; Herráez, A.; Diez, J.C. Ganoderma lucidum induced apoptosis in NB4 human leukemia cells: Involvement of Akt and Erk. J. Ethnopharmacol. 2010, 128, 71-78.

9. Ferreira, I.C.F.R.; Heleno, S.A.; Reis, F.S.; Stojković, D.; Queiroz, M.J.R.P.; Vasconcelos, M.H.; Soković, M. Chemical features of Ganoderma polysaccharides with antioxidant, antitumor and antimicrobial activities. Phytochemistry 2015, 114, 38-55.

10. Thyagarajan, A.; Jedinak, A.; Nguyen, H.; Terry, C.; Baldridge, L.A.; Jiang, J.; Sliva, D. Triterpenes from Ganoderma lucidum induce autophagy in colon cancer through the inhibition of $\mathrm{p} 38$ mitogen-activated kinase (p38 MAPK). Nutr. Cancer 2010, 62, 630-640.

11. Hossain, A.; Radwan, F.F.Y.; Doonan, B.P.; God, J.M.; Zhang, L.; Bell, P.D.; Haque, A. A possible cross-talk between autophagy and apoptosis in generating an immune response in melanoma. Apoptosis 2012, 17, 1066-1078.

12. Liang, C.; Li, H.; Zhou, H.; Zhang, S.; Liu, Z.; Zhou, Q.; Sun, F. Recombinant Lz-8 from Ganoderma lucidum induces endoplasmic reticulum stress-mediated autophagic cell death in SGC-7901 human gastric cancer cells. Oncol. Rep. 2012, 27, 1079-1089.

13. Oliveira, M.; Reis, F.S.; Sousa, D.; Tavares, C.; Lima, R.T.; Ferreira, I.C.F.R.; dos Santos, T.; Vasconcelos, M.H. A methanolic extract of Ganoderma lucidum fruiting body inhibits the growth of a gastric cancer cell line and affects cellular autophagy and cell cycle. Food Funct. 2014, 5, 1389-1394.

14. Funderburk, S.F.; Wang, Q.J.; Yue, Z. The Beclin 1-VPS34 complex-At the crossroads of autophagy and beyond. Trends Cell. Biol. 2010, 20, 355-362.

15. Mizushima, N.; Yoshimori, T.; Levine, B. Methods in mammalian autophagy research. Cell 2010, 140, 313-326.

16. Seca, H.; Lima, R.T.; Lopes-Rodrigues, V.; Guimarães, J.E.; Almeida, G.M.; Vasconcelos, M.H. Targeting miR-21 induces autophagy and chemosensitivity of leukemia cells. Curr. Cancer Drug Targets 2013, 14, 1135-1143.

17. Ichimura, Y.; Komatsu, M. Selective degradation of p62 by autophagy. Semin. Immunopathol. 2010, 32, 431-436.

18. Cerniglia, G.J.; Karar, J.; Tyagi, S.; Christofidou-Solomidou, M.; Rengan, R.; Koumenis, C.; Maity, A. Inhibition of autophagy as a strategy to augment radiosensitization by the dual phosphatidylinositol 3-kinase/mammalian target of rapamycin inhibitor NVP-BEZ235. Mol. Pharmacol. 2012, 82, 1230-1240. 
19. Heleno, S.A.; Ferreira, I.C.F.R.; Esteves, A.P.; Ćirić, A.; Glamočlija, J.; Martins, A.; Soković, M.; Queiroz, M.J.R.P. Antimicrobial and demelanizing activity of Ganoderma lucidum extract, p-hydroxybenzoic and cinnamic acids and their synthetic acetylated glucuronide methyl esters. Food Chem. Toxicol. 2013, 58, 95-100.

20. Cai, S.; Wang, O.; Wang, M.; He, J.; Wang, Y.; Zhang, D.; Zhou, F.; Ji, B. In vitro inhibitory effect on pancreatic lipase activity of subfractions from ethanol extracts of fermented oats (Avena sativa L.) and synergistic effect of three phenolic acids. J. Agric. Food Chem. 2012, 60, 7245-7251.

21. Lin, C.-J.; Lee, C.-C.; Shih, Y.-L.; Lin, T.-Y.; Wang, S.-H.; Lin, Y.-F.; Shih, C.-M. Resveratrol enhances the therapeutic effect of temozolomide against malignant glioma in vitro and in vivo by inhibiting autophagy. Free Radic. Biol. Med. 2012, 52, 377-391.

22. Vaz, J.A.; Almeida, G.M.; Ferreira, I.C.F.R.; Martins, A.; Vasconcelos, M.H. Clitocybe alexandri extract induces cell cycle arrest and apoptosis in a lung cancer cell line: Identification of phenolic acids with cytotoxic potential. Food Chem. 2012, 132, 482-486.

23. Weng, C.-J.; Yen, G.-C. Chemopreventive effects of dietary phytochemicals against cancer invasion and metastasis: Phenolic acids, monophenol, polyphenol, and their derivatives. Cancer Treat. Rev. 2012, 38, 76-87.

24. Gonzáles-Vallinas, M.; Gonzáles-Catejón, M.; Rodríguez-Casado, A.; de Molina, A.R. Dietary phytochemicals in cancer prevention and therapy: A complementary approach with promising perspectives. Nutr Rev. 2013, 71, 585-599.

25. Heleno, S.A.; Barros, L.; Martins, A.; Queiroz, M.J.R.P.; Santos-Buelga, C.; Ferreira, I.C.F.R. Fruiting body, spores and in vitro produced mycelium of Ganoderma lucidum from Northeast Portugal: A comparative study of the antioxidant potential of phenolic and polysaccharidic extracts. Food Res. Int. 2012, 46, 135-140.

26. Monks, A.; Scudiero, D.; Skehan, P.; Shoemaker, R.; Paull, K.; Vistica, D.; Hose, C.; Langley, J.; Cronise, P.; Vaigro-Wolff, A.; et al. Feasibility of a high-flux anticancer drug screen using a diverse panel of cultured human tumor cell lines. J. Natl. Cancer Inst. 1991, 83, 757-766.

27. Pankiv, S.; Clausen, T.H.; Lamark, T.; Brech, A.; Bruun, J.A.; Outzen, H.; Overvatn, A.; Bjorkoy, G.; Johansen, T. p62/SQSTM1 binds directly to Atg8/LC3 to facilitate degradation of ubiquitinated protein aggregates by autophagy. J. Biol. Chem. 2007, 282, 24131-24145.

28. Birame, B.M.; Jigui, W.; Fuxian, Y.; Shuang, W.; Li, Y.D.; Jiazeng, S.; Zhili, L.; Bao, Y.; Weiquan, L. Co-expression of apoptin (VP3) and antibacterial peptide cecropin B mutant (ABPS1) genes induce higher rate of apoptosis in HepG2 and A375 cell lines. Afr. J. Biotechnol. 2012, 11, 10981-10988.

29. Lima, R.T.; Barron, G.A.; Grabowska, J.A.; Bermano, G.; Kaur, S.; Roy, N.; Vasconcelos, M.H.; Lin, P.K.T. Cytotoxicity and cell death mechanisms induced by a novel bisnaphthalimidopropyl derivative against the NCI-H460 non-small lung cancer cell line. Anticancer Agents Med. Chem. 2013, 13, 414-421.

Sample Availability: Mushroom voucher specimens are available from the authors.

(C) 2015 by the authors; licensee MDPI, Basel, Switzerland. This article is an open access article distributed under the terms and conditions of the Creative Commons Attribution license (http://creativecommons.org/licenses/by/4.0/). 